\title{
Admission assessment: Linking a standardized admission exam to nursing program outcomes
}

\author{
Anita C. Reinhardt, Ph.D.
}

Teresa Keller, Ph.D.

Alyce Kolenovsky, M.PH.

Hallie Keller, M.S.

Pamela Schultz, Ph.D.

New Mexico State University School of Nursing

\begin{abstract}
This article reports the results of an academic program evaluation in which standardized admission test scores are compared to intermediate and final program outcomes. We used two intermediate program measures of progress-first semester nursing grades and performance on a standardized exit exam prior to graduation. Program final outcomes compared are student attrition and graduate nurses' performance on the NCLEX-RN. The analysis resulted in identifying statistically significant relationships between entrance exam scores and first semester grades. Statistically significant relationships were seen between entrance exam scores and performance on a pre-graduation exit exam. There was a statistically significant relationship between entrance exam scores and NCLEX-RN $N^{\circ}$ pass rates. These results indicate that admission testing is a viable option for use as part of an admission process for baccalaureate nursing programs.
\end{abstract}

\section{Introduction}

T he continued challenge for schools of nursing is to balance workforce demands for graduate nurses against the limitations of available academic resources. The goal is to admit the best-qualified students most likely to successfully complete a rigorous professional education program of study. To accomplish this goal, nursing schools develop criteria for admission and selection standards that may include scores obtained on standardized admission tests.

There are several commercially developed, nationally-normed admission exams available to nursing schools. The purpose of all these exams is to determine if applicants possess the foundational knowledge necessary for learning complex nursing curriculum content. For our school, we use the Health Education Systems, Inc. (HESI) Admission Assessment Exam (A2) as part of our admission criteria and we also use the HESI Exit Exam (E2) to measure the end-of-program-knowledge outcomes of our graduates in preparation for the national licensing exam.

As part of the ongoing evaluation of the education programs offered by our school of nursing, we examined the relationship between student scores on the $A 2$ and the predictors of student program

REINHARDT, KELLER, KOLENOVSKY, KELLER, \& SCHULTZ / DOI: 10.5929/9.2.1 
success: grades, attrition, performance on a standardized exit exam, and performance in the licensing exam. Specifically, we compared student admission scores to

- grades earned in first-semester nursing courses,

- attrition rates and program completion rates,

- performance on a standardized HESI exit exam (E2) taken prior to graduation,

- passage of the NCLEX-RN exam on the first attempt.

\section{Background}

There is significant debate that the use of standardized tests may restrict progress for students who are otherwise prepared for successful licensure (Bussen, 2016; Dinatale Stoehr, 2014; Morin, 2006; Morrison, Adamson, Nibert, \& Hsia, 2008; Nibert \& Morrison, 2013; Nibert et al., 2006; Nibert \& Young, 2008; Nibert, Young, \& Adamson, 2008; Nibert, Young, Adamson, Spurlock, \& Hanks, 2005; Spurlock, 2006; Spurlock \& Hanks, 2004; Sullivan, 2011). However, other authors have supported the careful use of these assessment tools as a way to promote student success. These assessment tests could become a significant predictor, along with other measures, of education program quality (English \& Gordon, 2008; Harding, 2010; Lavandera et al., 2011; Morrison, Adamson, Nibert, \& Hsia , 2008; Morrison, Free, \& Newman, 2008; Murray, Merriman, \& Adamson, 2008; Randolph, 2017; Sosa \& Sethares, 2015). These other common measures of program outcomes include completion rates, program attrition rates and, in some cases, performance on exit exams and performance on National Council Licensure Examination (NCLEX-RN ${ }^{\bullet}$ ).

Assessment exams provide a snapshot of the knowledge required for nursing studies and provide some indication of the student's academic preparation. Grossbach \& Kuncel (2011) published a meta-analysis that compared the general pre-college assessment exams (SAT and ACT) and student grade point average (GPA) to NCLEX-RN ${ }^{\oplus}$ passage. These assessments show some relationship to progression and success (Grossbach \& Kuncel, 2011). However, Hinderer, DiBartolo, and Walsh (2014) found in their pilot study of 89 students that the HESI A2 score, preadmission GPA and science GPA had no significant relationship to each other. The A2 exam was correlated to the nursing GPA and NCLEX-RN ${ }^{\circledR}$ success but not with timely program progression (Hinderer, DiBartolo, \& Walsh, 2014). Snyder and Hansen (2018) examined the admission criteria and performance on the NCLEX-RN ${ }^{\bullet}$ exam using the A2 exam as one of the admission criteria. Although the study did not predict success or failure on the licensing exam, higher student scores on the progression HESI exams and persistence to program completion were associated with NCLEX-RN ${ }^{\circ}$ success (Snyder, 2018). While there is evidence to support the use of the A2 for the selection process into nursing school, there is less evidence of the relationship between A2 scores and student attrition to program completion at graduation. Since an entrance exam, in this case, is meant to determine which applicants are the most likely to be prepared for academic success in a nursing curriculum, it was necessary to establish a "cut-score," or the minimum score on the A2 that students would need to attain for program application.

We developed three objectives for this program evaluation based on "cut-scores." They include:

- compare students' grades at the end of the first semester of studies to their A2 exam scores to determine an optimal cut-score for the HESI A2,

- evaluate student program attrition related to cut-scores, and

- assess HESI E2 and NCLEX-RN pass rates in relationship to cut-scores.

\section{Method}

REINHARDT, KELLER, KOLENOVSKY, KELLER, \& SCHULTZ / DOI: 10.5929/9.2.1 
This program evaluation was a retrospective review of aggregated, blinded student outcome data collected from 2004-2014. These analyses were conducted at a state-land grant university that is also designated as a Hispanic-Serving Institution (HSI). The undergraduate nursing student population is approximately $49 \%$ White, $50 \%$ Hispanic, and $1 \%$ other categories. For Stage One, the population group was 350 students. For stage two and stage three, the total population was 1,240 students admitted to the undergraduate nursing program. This review was approved by the university Institutional Review Board (IRB).

The evaluation was divided into three stages based on the objectives. When the use of the HESI A2 was instituted in this program, students were not required to obtain a minimal score before application. The first stage of this evaluation was to determine if a minimum admission score, or cut-score, would have a beneficial program effect. For Stage Two, we evaluated student attrition from the nursing program compared to the entrance cut-score and, for Stage Three, we examined the relationship between the cutscore and student success on the E2 and the NCLEX-RN ${ }^{\circ}$. Specifically, we wanted to determine if there was a relationship between the entrance exam scores and the number of student attempts to pass the E2 prior to graduation and the NCLEX-RN ${ }^{\circ}$ after graduation.

\section{Stage One: HESI Admission Assessment (A2) vs. First Semester Grades}

In this stage, we examined A2 scores compared to nursing course grades in the first semester of studies. Students were allowed two attempts to take the A2 during an admission cycle and we would use their best score for admission purposes. The scores included HESI A2 assessments of student knowledge in anatomy and physiology, biology, chemistry, grammar, math, reading, and vocabulary. HESI recommends a composite score of $75 \%$ or higher for program admission.

The first semester courses for the entering nursing students included Principles of Nursing for 8 credits, Health Assessment for 3 credits, Pharmacology for Clinical Nursing Practice for 4 credits (included dosage calculations), and Pathophysiology for 3 credits. Final course grades were reviewed for students ( $n=350)$ admitted between the fall semester 2004 and fall semester 2009. These grades were correlated to A2 composite scores and individual sub-scores using a Pearsons correlation test.

\section{Stage Two: Attrition and Graduation Rates}

The nursing program was initially a five-semester program that changed to a four-semester program in 2006. The expected time to program completion and graduation is four to five semesters with the understanding that some students might be held out a semester due to personal or academic reasons but still graduate within the four-five semester timeline. Attrition was defined as the number of students that either dropped out or failed out of the program. We defined our groups pre/and post- implementation of the cut-score. To assess attrition, we evaluated each cohort in each group by comparing the number of students admitted to a cohort to the number of students who graduated.

\section{Stage Three: Comparing A2 Scores to Repeated Attempts on E2 and NCLEX-RN ${ }^{\oplus}$ Exams}

Repeated testing affects later test scores as students gain experience with a standardized test (Spurlock, 2006). At this stage, we wanted to compare A2 scores to the number of student attempts to pass the E2 at the end of the program and the NCLEX-RN ${ }^{\circ}$ after graduation. HESI, INC at that time recommended a minimum passing score for the E2 of 850 . We compared the number of attempts to achieve an 850 on the E2 exam for both the pre-cut-score and post-cut-score groups. Students were allowed three attempts to pass

the

E2

exam.

REINHARDT, KELLER, KOLENOVSKY, KELLER, \& SCHULTZ / DOI: 10.5929/9.2.1 
Kaddoura, Flint, Van Dyke, Yang, and Chang (2017) found significantly better first time NCLEX-RN ${ }^{\circledR}$ pass rates for second-degree seeking nursing students than for those students obtaining their first undergraduate degree. We excluded this group from the analysis to control for possible skew related to the higher performance of second-degree seeking students on the licensing exam. The number HESI E2 exam attempts to score 850 or greater was compared to A2 scores to determine any predictive feature of these exams. Student scores were compared for both exams for graduated cohorts admitted between 2004 and $2013(n=1070)$.

\section{Results}

\section{Admission Assessment HESI (A2) vs. First Semester Nursing Course Grades ( $n=350$ )}

First, a review of student HESI A2 scores were compared to student final grades from their first nursing semester courses. Admission Assessment HESI (A2) scores showed a statistically significant correlation to the course grades (the higher the test score, the higher the course grade) ( $n=350)$. Using multiple regression models revealed that some HESI scores were predictive of course success (Table 1 ). The HESI exams in biology $(.187, p=0.004)$, grammar $(.289, p<0.0001)$, and math $(.219, p=0.0003)$ were predictive of successful completion of the Principles course. The HESI exams in anatomy and physiology (.164, $p=$ $0.02)$, grammar $(.166, p=0.02)$, and math $(.162, p=0.01)$ were predictive of successful completion of the Health Assessment course. The HESI exams in anatomy and physiology (.158, $p=0.02)$, grammar (.137, $p$ $=0.04)$, and math $(.256, p<0.0001)$ were predictive of successful completion of the Pharmacology course. The HESI exams in anatomy and physiology $(.161, p=0.02)$, grammar $(.162, p=0.02)$, and math $(.255, p<$ 0.0001 ) were predictive of successful completion of the Pathophysiology course. The greater the score on the HESI A2, the higher the grade was in the first semester course. While all the HESI A2 exams (anatomy and physiology, biology, chemistry, grammar, math, reading, and vocabulary) correlated to the first semester courses of the program, only anatomy and physiology, biology, grammar, and math exams reached statistical significance (See Table 1 ).

Table 1

First Semester Courses vs. HESI Admission Assessment Exams (A2) 2004-2006 ( $n=350)$

\begin{tabular}{lccll}
$\begin{array}{l}\text { Course Passage with } \\
\text { a 76\% or better grade }\end{array}$ & HESI A\&P & HESI Biology & HESI Grammar & \multicolumn{1}{c}{ HESI Math } \\
\hline Principles & & $.187, p=0.004$ & $.289, p<0.0001$ & $.219, p=0.0003$ \\
Health Assessment & $.164, p=0.02$ & & $.166, p=0.02$ & $.162, p=0.01$ \\
Pharmacology & $.158, p=0.02$ & $.137, p=0.04$ & $.256, p<0.0001$ \\
Pathophysiology & $.161, p=0.02$ & & $.162, p=0.02$ & $.255, p<0.0001$ \\
\hline
\end{tabular}

\section{Program Attrition and Completion}

Second, students who were admitted to the program prior to a cut-score implementation in 2010 were compared to students after the cut-score related to persistence/attrition (See Table 2). To determine whether the cut-score for program entry showed a significant correlation with student completion rates, we performed an interrupted time series logistic regression using the data in Table 4. The dependent variable in our regression is a binary indicator of whether a student completed the program or failed/withdrew. The independent variables include: Post- $\mathrm{Cu}=$ binary indicator of whether the student was admitted before or after implementing the cut-score; Admission Year = the year in which the student was admitted; and Year Post-Cut = the number of years after implementation of the cut-score that the student was admitted (for example, a student admitted any year before 2010 would have a value of 0 , a student admitted in 2010 would have a value of 1 , a student admitted in 2011 would have a value of 2,

REINHARDT, KELLER, KOLENOVSKY, KELLER, \& SCHULTZ / DOI: 10.5929/9.2.1 
etc.). We also performed a Hosmer-Lemeshow test to check the goodness of fit of our model= (See Table 3).

Table 2

Program Completion

\begin{tabular}{cccc}
\hline $\begin{array}{c}\text { Year } \\
\text { Entered/Completed }\end{array}$ & Program Completion/Admitted & $\begin{array}{c}\text { Completion } \\
\text { Percentage }\end{array}$ & $\begin{array}{c}\text { Attrition } \\
\text { Percentage }\end{array}$ \\
\hline $2004 / 2006$ & $90 / 100$ & $81.82 \%$ & $18.18 \%$ \\
$2005 / 2007$ & $99 / 117$ & $84.62 \%$ & $15.58 \%$ \\
$2006 / 2008$ & $113 / 125$ & $90.4 \%$ & $9.6 \%$ \\
$2007 / 2009$ & $77 / 110$ & $76.24 \%$ & $23.76 \%$ \\
$2008 / 2010$ & 158.192 & $82.29 \%$ & $17.71 \%$ \\
$2009 / 2011$ & $79 / 101$ & $78.22 \%$ & $21.78 \%$ \\
\hline Post-cut-score & $91 / 97$ & $93.81 \%$ & $6.19 \%$ \\
$2010 / 2012$ & $101 / 110$ & $91.82 \%$ & $8.18 \%$ \\
\hline $2011 / 2013$ & $151 / 167$ & $90.42 \%$ & $9.58 \%$ \\
$2012 / 2014$ & $111 / 120$ & $92.50 \%$ & $7.50 \%$ \\
\hline $2013 / 2015$ & Average & $86.29 \%$ & $13.71 \%$ \\
\hline Program Total Over & & & \\
10 Years & &
\end{tabular}

Table 3

Interrupted Time Series Regression

\begin{tabular}{|c|c|c|c|c|c|}
\hline \multicolumn{6}{|l|}{ Coefficients } \\
\hline & & $B$ & S.E. & Z & Sig. \\
\hline \multicolumn{2}{|l|}{ Intercept } & 147.578 & 117.660 & 1.254 & 0.210 \\
\hline \multicolumn{2}{|l|}{ Post-Cut* } & 1.233 & 0.484 & 2.546 & 0.011 \\
\hline \multicolumn{2}{|c|}{ Admission Year } & -0.073 & 0.059 & -1.241 & 0.215 \\
\hline \multicolumn{2}{|l|}{ Year Post-Cut } & 0.001 & 0.168 & 0.008 & 0.994 \\
\hline \multicolumn{6}{|c|}{$*$ significant at $\alpha=0.05$} \\
\hline \multicolumn{3}{|c|}{ Hosmer-Lemeshow Test } & & & \\
\hline Chi-square & $\mathrm{df}$ & Sig. & & & \\
\hline 8.2635 & 8 & 0.4082 & & & \\
\hline
\end{tabular}

The results of the regression are shown in Table 3 . We see that there is a significant difference in completion rates for students admitted before the cut-score was implemented and students admitted afterward $(p=0.011)$. In particular, students admitted after implementation of the cut-score are more likely to complete the program rather than fail or withdraw. The Hosmer-Lemeshow test results indicate that the model fits the data well $(p>0.05)$.

\section{Comparing A2 to First Attempt at the NCLEX-RN ${ }^{\circledR}(n=350)$}

We reviewed the data to find the relationship of the A2 scores for the initial student group ( $n=350$ ) analysis to the first and second attempts of the NCLEX-RN ${ }^{\bullet}$ licensure exam. Using a t-test, significant 
statistical relationships were found in the initial study sample $(n=350)$ of $A 2$ scores to the passage of the NCLEX-RN ${ }^{\bullet}$ licensing exam (See Table 4). Scores of 70 or greater on the HESI anatomy and physiology exam $\left(\mathrm{M}=70.4, \pm 12.6, \mathrm{p}=0.002\right.$ ) were statistically significant to first attempt NCLEX-RN ${ }^{\circledR}$ passage. Scores of 77 or greater on the HESI biology exam ( $M=77.4, \pm 11.1, p=0.0001)$ were statistically significant to first attempt NCLEX-RN ${ }^{\circ}$ passage. Scores of 76 or greater on the HESI chemistry exam $(M=76.4, \pm 12.3, p=$ 0.02 ) were statistically significant to first attempt NCLEX-RN ${ }^{\circ}$ passage. Scores of 83 or greater on the HESI reading exam $(M=83.8, \pm 8.8, p=0.0004)$ were statistically significant to first attempt NCLEX-RN ${ }^{\bullet}$ passage. Scores of 79 or greater on the HESI vocabulary exam (M $=79.2, \pm 13.6, p=0.001)$ were statistically significant to first attempt NCLEX-RN ${ }^{\oplus}$ passage. Scores of 80 or greater on the HESI composite score $(M=$ $80.5, \pm 6.9, p<0.00001$ ) were statistically significant to first attempt NCLEX-RN ${ }^{\oplus}$ passage. The results of this analysis allowed us to set a "cut-score" of $78 \%$ for admission.

Table 4

NCLEX-RN $1^{\text {st }}$ Attempt Pass Rate Compared to A2 Pre-Cut-Score $(n=350)$

\begin{tabular}{llll}
\hline $\begin{array}{c}\text { HESI Admission } \\
\begin{array}{c}\text { Assessment Exam } \\
\text { (A2) }\end{array}\end{array}$ & $\begin{array}{c}\text { NCLEX-RN }{ }^{\bullet} \mathbf{1}^{\text {st }} \text { Attempt } \\
\text { Pass }\end{array}$ & $\begin{array}{r}\text { NCLEX-RN } \mathbf{2}^{\text {nd }} \text { or more } \\
\text { Attempt Pass }\end{array}$ & \multicolumn{1}{c}{ p-value } \\
\hline $\begin{array}{l}\text { Anatomy \& } \\
\text { Physiology }\end{array}$ & $\mathrm{M}=70.4, \pm 12.6$ & $\mathrm{M}=63.9, \pm 12.1$ & $\mathrm{p}=0.002$ \\
Biology & $\mathrm{M}=77.4, \pm 11.1$ & $\mathrm{M}=65.2, \pm 13.3$ & $\mathrm{p}=0.0001$ \\
Chemistry & $\mathrm{M}=76.4, \pm 12.3$ & $\mathrm{M}=71.1, \pm 14.4$ & $\mathrm{p}=0.02$ \\
Reading & $\mathrm{M}=83.8, \pm 8.8$ & $\mathrm{M}=77.7, \pm 13.4$ & $\mathrm{p}=0.0004$ \\
Vocabulary & $\mathrm{M}=79.2, \pm 13.6$ & $\mathrm{M}=70.4, \pm 18.6$ & $\mathrm{p}=0.001$ \\
Composite & $\mathrm{M}=80.5, \pm 6.9$ & $\mathrm{M}=74.5, \pm 8.5$ & $\mathrm{p}<0.00001$ \\
\hline
\end{tabular}

\section{HESI Exit Exam Scores and NCLEX-RN ${ }^{\bullet}$ Pass Attempts}

Finally, all student graduates HESI E2 scores were compared to the first attempt passage of the NCLEX$\mathrm{RN}^{\oplus}$ licensing exam $(n=1070)$. Overall NCLEX-RN ${ }^{\oplus}$ pass rates during this period seem unchanged. As we compared our average HESI E2 scores to the NCLEX-RN ${ }^{\circ}$ first attempt pass rates, we see some program improvement, but the results are not statistically significant.

After removing second-degree students (Kaddoura, Flint, Van Dyke, Yang, \& Chiang, 2017), the average numbers of HESI E2 attempts appear right-skewed both before and after implementation of the cut-score. The Fligner-Killeen shows no difference in variance between the two distributions $(p=0.9364)$. Because the two distributions are asymmetric with homogeneity of variance, a Mann-Whitney $U$ Test is used to test for a difference in the distributions. The Mann-Whitney $U$ Test shows no significant difference between the average number of HESI attempts of pre-cut students and those of post-cut students $(p=$ 0.1060)(See Figure 1) 


\section{Pre-Cut Mean Number of HESI Attempts}

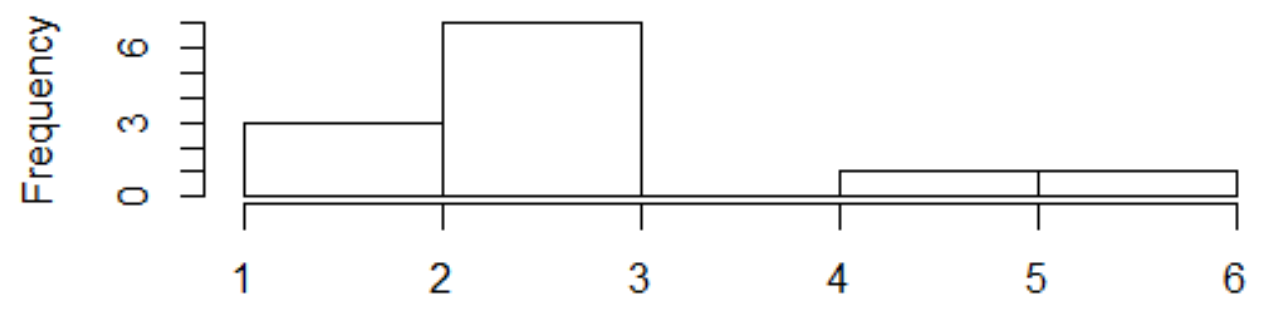

Number of Attempts

\section{Post-Cut Mean Number of HESI Attempts}

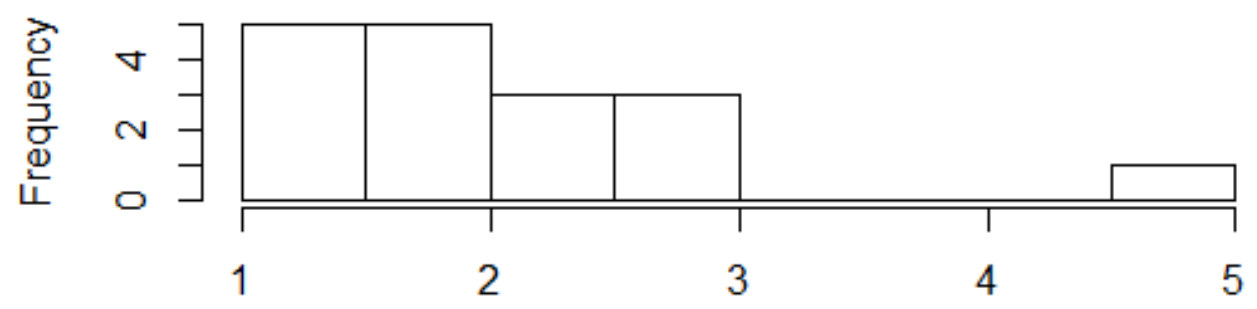

Number of Attempts

Figure 1. HESI E2 Attempts $(n=1070)$

For additional analysis, we compared pre/post A2 cut-score groups with NCLEX attempts after graduation. After removing second-degree students, the average numbers of NCLEX ${ }^{\circ}$ attempts appear right-skewed both before and after the implementation of the cut-scores. The Fligner-Killeen shows no difference in variance between the two distributions $(p=0.9364)$. Because the two distributions are asymmetric with homogeneity of variance, a Mann-Whitney $U$ Test is used to test for a difference in the distributions. The Mann-Whitney $U$ Test shows no significant difference between the average number of NCLEX ${ }^{\circ}$ attempts of pre-cut students and those of post-cut students $(p=0.1060)$ (See Figure 2$)$. 


\section{Pre-Cut Mean Number of NCLEX Attempts}

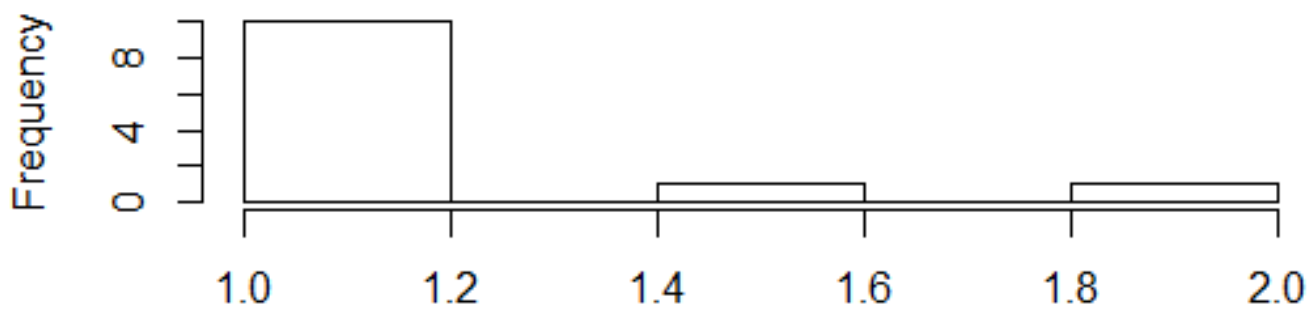

Number of Attempts

Post-Cut Mean Number of NCLEX Attempts

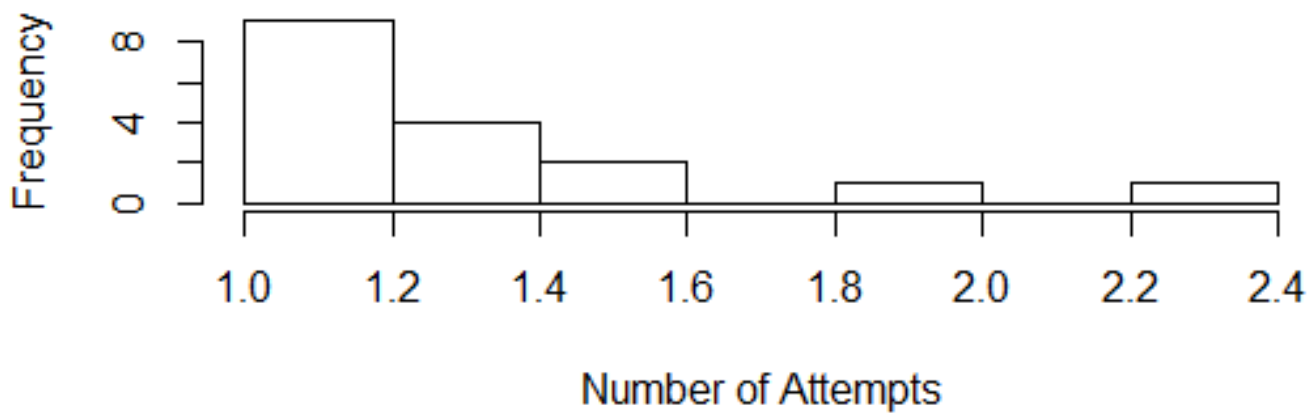

Figure 2. Number of NCLEX-RN ${ }^{\circledR}$ Attempts.

\section{Discussion}

Initially, we assessed the relationship between the A2 exam and first-semester nursing course grades. Success or failure in the first semester courses was highly correlated to A2 subcategory scores. We determined a composite score of 78 with at least $75 \%$ on each subscale was required for our applicant population to be successful in the first semester of nursing studies. Prior to this program evaluation, there was no required A2 exam score for admission. However, after the implementation of the "cut-score," more students were able to pass the HESI E2 on the first attempt than pre-cut-score test-takers.

At the time of the exam composite score/course grade comparison, the first-semester course load was 18-semester credits. This was a very heavy course load and students struggled. After the adoption of the cut-score, we moved the Pathophysiology course to prerequisite status for program admission. This allowed for a logical progression from anatomy and physiology courses into pathophysiology prior to admission to the nursing program and lessened the workload for first-semester students.

For the second stage, levels of student attrition and program completion since instituting HESI A2 testing in 2004 were addressed. The national average for student completion of BSN programs is about $67 \%$ with an attrition rate of $33 \%$ ( $A A C N, 2018$ ). In reviewing the number of semesters taken to graduate, we have found that the percentage of graduated students $(n=1070)$ persisting in the program (finishing in $4-5$

REINHARDT, KELLER, KOLENOVSKY, KELLER, \& SCHULTZ / DOI: 10.5929/9.2.1 
semesters) increased to $90.8 \%$ over the 10 -year assessment period. Attrition for this same time period decreased to $13 \%$ on average with a drop to as low as $6 \%$ following the implementation of the cut-score.

The relevance of the NCLEX-RN ${ }^{\circ}$ passage to the HESI E2 has been studied by others and many have found significant licensure exam success, (Johnson, Sanderson, Wang, \& Parker, 2017) but we wanted to see if the predictive value of the HESI A2 exam could be applied to the NCLEX-RN ${ }^{\circ}$ as well. As we saw little connection between $\mathrm{A} 2$ and NCLEX-RN ${ }^{\circ}$ success in the overall sample, we believe there are additional variables over the course of two years that influence student success (Wilkinson, 2018). Many of these variables are personal experiences (marriage, illness, finances) that are difficult to quantify and measure in a program assessment.

\section{Conclusion}

The establishment of a minimum HESI A2 composite score has strengthened the program and allowed earlier identification of students at risk. The composite score is predictive of student success in their first semester of the nursing program. The progression and retention rates reflect that the students who were accepted after the cut-score was enacted showed a significant increase in program completion numbers and a significant drop in attrition.

For the purpose of program evaluation, we have found that the A2 can assist us with selecting students who are likely to successfully complete the baccalaureate nursing program. Certainly, this is seen in firstsemester grades, although, grades obtained after the first semester were not analyzed. We did not analyze additional grades because our purpose was to evaluate success in the first-semester grades, attrition, and success in the E2 and NCLEX-RN ${ }^{\circ}$ pass rates. This is a limitation that could be addressed in further program evaluation.

In terms of attrition, we found our attrition improved after the initiation of a cut-score. However, we suspect students admitted pre-cut-score may not have studied prior to taking the A2 exam while students admitted after may have studied more to ensure successful admission to the program. It is possible that students admitted after the cut-score implementation may be more motivated and, therefore, more likely

to study after admission to the program (Labrague, McEnroe-Petitte, Fronda, \& Obeidat, 2018). The attrition rate indicates that students were more likely to experience successful program progress to completion.

Future program assessment could be designed to help capture the effect of "soft" variables such as financial concerns or life events that distract or support program completion. For example, we evaluated students who did not complete the program due to personal illness or family concerns. Program assessment could be informed by qualitative investigations such as exit interviews and by comparing indicators of socioeconomic statuses, such as financial aid, and site secondary education to the program outcomes examined in this assessment. The impact of changing the placement of pathophysiology on A2 and E2 scores was not evaluated but would be included in the next cycle of assessment. However, based on these analyses, using the $A 2$ with a cut-score derived from the performance of our own student population has helped us to optimize student progression and ultimate success without increasing our program costs.

\section{References}

AACN. (2018). 2017-2018 Enrollment and graduations in baccalaurate and graduateprograms in nursing. Retrieved from Washington, DC:

Bussen, J. (2016). Nursing students' nonacademic barriers to success on high stakes exams. In L. Candela, A. Corkill, R. Serafica, \& C. Yucha (Eds.): ProQuest Dissertations Publishing.

REINHARDT, KELLER, KOLENOVSKY, KELLER, \& SCHULTZ / DOI: 10.5929/9.2.1 
Dinatale Stoehr, A. (2014). Predictors of success on the National Council Licensure Examination for Registered Nurses (NCLEX-RN) in a traditional baccalaureate nursing program: A descriptive study. In M. Kodadek, J. McDaniel, \& C. Urban (Eds.): ProQuest Dissertations Publishing.

English, J. B., \& Gordon, D. K. (2008). Successful student remediation following repeated failures on the HESI exam. Nurse Educator, 75S-777. Retrieved from http://catalog2.nmsu.edu:2048/login?url=http://search.ebscohost.com/login.aspx?direct=true\& $\underline{\mathrm{db}=\mathrm{rzh} \& A \mathrm{~N}=2010189330 \& \text { site }=\text { ehost-live \&scope }=\text { site }}$

Grossbach, A., \& Kuncel, N. (2011). The predictive validity of nursing admission measures for performance on the National Council Licensure Examination: A meta-analysis. Journal of Professional Nursing, 27(2), 124-128. Retrieved from http:// catalog2.nmsu.edu:2048/login?url=http://search.ebscohost.com/login.aspx?direct=true\&db=rzh \&AN=2011270115\&site=ehost-live \&scope=site

Harding, M. (2010). Predictability associated with exit examinatios: A literature review. In J. Nurs. Educ. (Vol. 49, pp. 493-497): SLACK INC.

Hinderer, K. A., DiBartolo, M. C., \& Walsh, C. M. (2014). HESI admission assessment (A(2)) examination scores, program progression, and NCLEX-RN success in baccalaureate nursing: An exploratory study of dependable academic indicators of success. J Prof Nurs, 30(5), 436-442. doi:10.1016/j.profnurs.2014.01.007

Johnson, T., Sanderson, B., Wang, C. H., \& Parker, F. (2017). Factors associated With first-time NCLEX-RN success: A descriptive research study. J Nurs Educ, 56(9), 542-545. doi:10.3928/0148483420170817-05

Kaddoura, M. A., Flint, E. P., Van Dyke, O., Yang, Q., \& Chiang, L. C. (2017). Academic and demographic predictors of NCLEX-RN prss rates in first- and second-degree accelerated BSN programs. J Prof Nurs, 33(3), 229-240. doi:10.1016/j.profnurs.2016.09.005

Labrague, L. J., McEnroe-Petitte, D. M., Fronda, D. C., \& Obeidat, A. A. (2018). Interprofessional simulation in undergraduate nursing program: An integrative review. Nurse Educ Today, 67, 4655. doi:10.1016/j.nedt.2018.05.001

Lavandera, R., Whalen, D., Perkel, L., Hackett, V., Molnar, D., Steffey, C., ... Harris, J. (2011). Value-added of HESI exam as a predictor of timely first-time RN licensure. International Journal of Nursing Education Scholarship, 8(1), 1-12. Retrieved from http:// catalog2.nmsu.edu:2048/login?url=http://search.ebscohost.com/login.aspx?direct=true\&db=rzh $\& A N=2011305737 \&$ site $=$ ehost-live \&scope $=$ site

Morin, K. H. (2006). Commentary: use of the HESI exit examination in schools of nursing. Commentary from the perspective of an expert in academic policy. Journal of Nursing Education, 45(8), 308309. Retrieved from Publisher URL: www.cinahl.com/cgibin/refsvc?jid=227\&accno=2009268963

Morrison, S., Adamson, C., Nibert, A., \& Hsia, S. (2008). HESI exams: an overview of reliability and validity. Comput Inform Nurs 2004;22(4):220-226. Nurse Educator, 39S-45s. Retrieved from http://catalog2.nmsu.edu:2048/login?url=http://search.ebscohost.com/login.aspx?direct=true\& $\underline{\mathrm{db}=r z h \& A N=2010189154 \& \text { site }=\text { ehost-live \&scope }=\text { site }}$ 
Morrison, S., Free, K. W., \& Newman, M. (2008). Do progression and remediation policies improve NCLEX-RN pass rates? Nurs Educ; 27(2):94-96. Nurse Educator, 67S-69. Retrieved from http://catalog2.nmsu.edu:2048/login?url=http://search.ebscohost.com/login.aspx?direct=true\& $\underline{\mathrm{db}=r z h \& A N=2010189322 \& \text { site }=\text { ehost-live \&scope }=\text { site }}$

Murray, K. T., Merriman, C. S., \& Adamson, C. (2008). Use of the HESI admission assessment to predict student success. Comput Inform Nurs; 26(3):167-172. Nurse Educator, 61S-666. Retrieved from http://catalog2.nmsu.edu:2048/login?url=http://search.ebscohost.com/login.aspx?direct=true\& $\underline{\mathrm{db}=r z h \& A N=2010189320 \& \text { site=ehost-live \&scope }=\text { site }}$

Nibert, A., \& Morrison, S. (2013). HESI testing--a history of evidence-based research. J Prof Nurs, 29(2 Suppl 1), S2-4. doi:10.1016/j.profnurs.2012.06.004

Nibert, A. T., Adamson, C., Young, A., Lauchner, K. A., Britt, R. B., \& Hinds, M. N. (2006). C Choosing a theoretical framework to guide HESI exit examination research. J Nurs Educ, 45(8), 303-307. Retrieved from https://www.ncbi.nlm.nih.gov/pubmed/16915987

Nibert, A. T., \& Young, A. (2008). A third study on predicting NCLEX success with the HESI exit exam. Comput Nurs; 19(4):172-178. Nurse Educator, 21S-227. Retrieved from http://catalog2.nmsu.edu:2048/login?url=http://search.ebscohost.com/login.aspx?direct=true\& $\mathrm{db}=\mathrm{rzh} \& A N=2010189141 \&$ site $=$ ehost-live \&scope $=$ site

Nibert, A. T., Young, A., \& Adamson, C. (2008). Predicting NCLEX success with the HESI exit exam: fourth annual validity study. Comput Inform Nurs; 20(6):261-267. Nurse Educator, 28S-34s. Retrieved from http://catalog2.nmsu.edu:2048/login?url=http://search.ebscohost.com/login.aspx?direct=true\& $\mathrm{db}=\mathrm{rzh} \& A \mathrm{~N}=2010189145 \&$ site=ehost-live \&scope $=$ site

Nibert, A. T., Young, A., Adamson, C., Spurlock, D., Jr., \& Hanks, C. (2005). Debate regarding interpretation of HESI exit examination scores. Journal of Nursing Education (Vol. 43, No. 12, pp. 539-545). Journal of Nursing Education, 44(3), 101-106. Retrieved from http://catalog2.nmsu.edu:2048/login?url=http://search.ebscohost.com/login.aspx?direct=true\& $\underline{\mathrm{db}=r z h \& A N=2005070987 \& \text { site }=\text { ehost-live \&scope }=\text { site }}$

Randolph, P. K. (2017). Standardized testing practices: Effect on Ggaduation and NCLEX(R) pass rates. J Prof Nurs, 33(3), 224-228. doi:10.1016/j.profnurs.2016.09.002

Snyder, T. (2018). The relationship between admission requirements, academic performance measures and undergraduate nursing student success. In M. A. Hansen (Ed.): ProQuest Dissertations Publishing.

Sosa, M. E., \& Sethares, K. A. (2015). An integrative review of the use and outcomes of HESI testing in baccalaureate nursing programs. Nursing Education Perspectives, 36(4), 237-243. doi:10.5480/14-1515

Spurlock, D., Jr. (2006). Do no harm: progression policies and high-stakes testing in nursing education. Journal of Nursing Education, 45(8), 297-302. Retrieved from http://catalog2.nmsu.edu:2048/login?url=http://search.ebscohost.com/login.aspx?direct=true\& $\underline{d b}=r z h \& A N=2009268948 \&$ site $=$ ehost-live \&scope $=$ site

Spurlock, D. R., Jr., \& Hanks, C. (2004). Establishing progression policies with the HESI exit examination: a review of the evidence. J Nurs Educ, 43(12), 539-545. Retrieved from https://www.ncbi.nlm.nih.gov/pubmed/15620067 
Sullivan, D. (2011). The utilization and effectiveness of the HESI E(square) exit exam as a graduation requirement toward increasing NCLEX-RN ${ }^{\circledR}$ pass rates in baccalaureate nursing programs. In $\mathrm{M}$. Bondmass, M. Clark, S. Kowalski, \& S. Moonie (Eds.): ProQuest Dissertations Publishing.

Wilkinson, E. (2018). Integration of learning activities for improved performance on the NCLEX-RN Exam. In K. Watson, E. Riester Green, \& M. Robb (Eds.): ProQuest Dissertations Publishing.

\section{About the Authors}

Anita C. Reinhardt (acrein@nmsu.eddu) served as the Associate Director for Undergraduate Nursing Programs during the study period. She is a graduate from the University of California, San Francisco where she earned her BSN and MSN. She further earned her PhD in Nursing from Oregon Health and Science University in Portland Oregon. Her research interests include studies to support student success and program evaluation.

Teresa Keller (tkeller@nmsu.edu) is a Professor of Nursing and Associate Dean of Academics for the College of Health and Social Services at New Mexico State University. Her research interests include the organization and administration of academic nursing programs.

Alyce Kolenovsky (aksky@nmsu.edu) is Lead Advisor for the BSN program at New Mexico State University. She has worked for the university for over 12 years and has been in data management positions for more than 30 years. She completed her Master's in Public Health Degree in 2015.

Hallie Keller (halliekeller@gmail.com) graduated with a Master's of Statistics from North Carolina State University in 2017. She enjoys working with socioeconomic data, and aspires to make statistics understandable to the public.

Pamela Schultz (pschultz@nmsu.edu) was the Director of the School of Nursing at New Mexico State University during the period of program study. She is currently retired and resides in Florida. 